\section{THE CHEMISTRY OF THE ALBUMINS.}

THE composition and constitution of the albumins have hitherto been studied almost exclusively from the analytical point of view, and particularly by the examination of the products of hydrolysis effected by either acids, alkalies, enzymes, or putrefactive bacteria.

Improved methods for the separation of these products, due to Kossel, E. Fischer, and others, have led to the conception of the complex albumin molecule as composed of a large number of simple molecules, consisting to a great extent of monamino- and diamino-acids and related compounds (compare NATURE, vol. lxv. p. 90), united together by some form of condensation, which involves an aminogroup, and is probably similar in nature to that which occurs in the formation of the acid amides.

The various members of the vast group of albuminous substances may differ from one another in many ways, but two of the chief points of difference appear to be the variety of these component groups, and the numbers of them contained in a single molecule. Thus a comparatively simple albuminoid substance, such as silk when it is completely hydrolysed, yields, among other products, the monaminoacids, tyrosine, phenylalanine, leucine, alanine (aminopropionic acid), and glycine (aminoacetic acid). Gelatin, on the other hand, which is also comparatively simple in composition, differs markedly from silk by the absence of tyrosine, whilst oxyhæmoglobin, to take another instance, yields tyrosine, but no glycine.

By the incomplete hydrolysis of the fibroin of silk, moreover, Prof. E. Fischer has obtained a substance which appears to be a compound of aminoacetic and aminopropionic acids. The formation of this substance is of great interest, since it probably represents an intermediate stage of the decomposition, and affords strong confirmation of the view of the constitution of the proteid molecule which has just been stated.

Most of the final products of hydrolysis of the albumins are familiar compounds which can readily be prepared by synthetic methods, but very little has hitherto been known of the more complex substances to be obtained by the linking together of several of these molecules. It is in this direction that Prof. Emil Fischer has been working for some time past, and he has contributed to the current number of the Berichte an account of the highly important results which have already been attained. The plan of attack consists in endeavouring to build up complex substances from the simple amino-acids by first introducing a second molecule of the same or another acid, and then repeating the process as frequently as possible with each successive product.

The first step was taken some time ago by the production of glycylglycine, $\mathrm{NH}_{2} \cdot \mathrm{CH}_{2} \cdot \mathrm{CO} \cdot \mathrm{NH} \cdot \mathrm{CH}_{2} \cdot \mathrm{CO}_{2} \mathrm{H}$, from glycine anhydride. This suistance contains two molecules of glycine united in the typical manner, and is the simplest of the polypeptides, as these bodies have been named, because of their assumed similarity to the peptones in structure. To add a third link to the chain is, however, a matter of difficulty, owing to the ease with which the aminongroup undergoes change. Two methods have, however, been found by means of which this can be accomplished.

The first of these consists in building up the new aminoacetic molecule by first introducing into the amino-group the chloracetyl radical, $\mathrm{Cl} \cdot \mathrm{CH}_{2} . \mathrm{CO}$. (by the action of chloracetyl chloride), and then introducing the amino-group by the action of ammonia, the final product being a crystalline substance having the formula of a diglycylglycine $\mathrm{NH}_{2} \cdot \mathrm{CH}_{2} \cdot \mathrm{CO} \cdot \mathrm{NH} . \mathrm{CH}_{2} \cdot \mathrm{CO} \cdot \mathrm{NH} \cdot \mathrm{CH}_{2} \cdot \mathrm{CO}_{2} \mathrm{H}$. A description of the properties and reactions of this substance has, unfortunately, not yet been published.

The other method consists in first of all introducing the group. $\mathrm{CO}_{2} \mathrm{C}_{2} \mathrm{H}_{5}$ into the amino-group of glycylglycine. The resulting compound can then be converted into an acid chloride, which readily reacts with the ester of glycine to form the desired compound containing three glycine molecules. A repetition of this process leads to the addition of a fourth glycine molecule to the chain, the final product which has hitherto been obtained being of the respectable complexity shown by the formula

$\mathrm{CO}_{2} \mathrm{C}_{2} \mathrm{H}_{5}$. NH.CH $\mathrm{CH}_{2}$ CO.NH.CHO.CO.NH.CH $\mathrm{CH}_{2}$.CO.NH.CH $\mathrm{CH}_{2} \mathrm{C}_{2} \mathrm{H}_{5}$ No. 1761, VOL. 68] (carboxethyl-triglycylglycine ester). This substance is crystalline and is converted by ammonia into a crystalline amide, which gives, with an alkali and a copper salt, the well-known biuret reaction, which is given by all the amides of this series, as well as by the albumins. The group . $\mathrm{CO}_{2} \mathrm{C}_{2} \mathrm{H}_{5}$ combined with the amino-group cannot, so far, be removed from the molecule, so that, until some means of doing this is discovered, this method can scarcely be expected to yield derivatives so closely related to the actual proteids as those obtained by the method first described.

Both methods obviously lend themselves to the production of a great variety of compounds containing different aminoacid groups, and substances of this kind, derived from glycine and leucine, and from glycine and alanine, have already been prepared. It seems probable that by their extended use compounds of the order of complexity of the peptones or albumoses may soon be prepared. The application of both methods is, indeed, still in its infancy, but we can have little doubt that the genius which laid bare the innermost secrets of the sugars will succeed in solving many of the problems which surround the chemistry of the albumins. arthur HardeN.

\section{THE ANTARCTIC EXPEDITIONS.}

$T H E$ report of Captain Scott to the presidents of the Royal and Royal Geographical Societies, which is printed in the July number of the Geographical Journal, adds a number of points of geographical interest to those previously published, especially with regard to the great southern ice-barrier, and the nature of the lands discovered by the British expedition; while the map published at the same time, which has had the advantage of revision by Lieut. Shackleton since that officer's arrival, permits the details of the narrative to be followed with much clearness, although it is still to be considered merely provisional.

The voyage down the east coast of Victoria Land brought to light some new features in the configuration of the country. Thus, in about lat. $75^{\circ} 30^{\prime}$, an enormous floe of the inland-ice was seen to descend into the sea and extend for many miles to seaward, closely resembling the Great Barrier and the barrier formation which entirely fills Lady Newnes Bay. Near the entrance to MacMurdo Strait (between Erebus and Terror Island and the mainland), icecliffs; 150 feet high, were again skirted, being evidently the seaward face of the great glacier subsequently explored by Lieut. Armitage. During the voyage eastward along the face of the Great Barrier, soundings for some time showed depths of more than 300 fathoms, the barrier edge being very irregular, and varying from 30 to 215 feet in height. In the neighbourhood of the eastern land discovered by the expedition (King Edward VII. Land) the soundings suddenly became less, varying from 70 to 100 fathoms. The bare patches seen among the snow slopes of the new land, which are evidently the sharp spurs of snow-capped hills, stand at a height of 2000 to 3000 feet. The balloon ascent and sledge expedition made in long. $196^{\circ} 15^{\prime}$, showed that the surface of the barrier ${ }^{1}$ undulated in long waves running W.S.W. and E.N.E. It was noticed that here the ship neither rose nor fell in relation to the ice, thus apparently indicating that the latter is floating.

The winter quarters were established in February, and the magnetic observatory was in readiness for the termday observations of March $\mathrm{I}$, all the subsequent term days being kept by Mr. Bernacchi without a break. On May 3 a strong southerly gale brought the first heavy snowfall, also blowing the strait clear of ice to within 200 yards of the ship. Mr. Hodgson was constantly engaged on his biological work, keeping holes open for his nets and fishtraps, and all the officers assisted Lieut. Royds in the night meteorological observations. Auroral displays were infrequent and feeble, but were carefully observed. The winter sledge reconnaissances revealed much of the topography of the neighbourhood, both on the south side of Erebus and Terror Island, and between it and the mainland, where there are three smaller islands, named White,

1 The whole southern ice-sheet is spoken of throughout as the "barrier. though this term would more naturally apply to its northern face only. 
Black, and Brown, from their characteristic aspects; the first being snow-covered, while the two others displayed the bare basaltic rocks of which they are composed. In September and October minimum temperatures of $-5^{\circ}$ and $-57^{\circ} \mathrm{F}$. were experienced during two of the journeys.

During a visit to Mount Terror, the eastern slopes of which are terribly wind-swept and bare to the summit, $\mathrm{Mr}$. Skelton made a perilous descent to the sea-ice and was su fortunate as to discover a breeding-place of the Emperor penguin, obtaining several specimens of the young in down, besides photographs and notes. The attacks of scurvy which occurred about this time, brought about by severe work and exposure, were in reality very slight, and their importance has been much exaggerated, all symptoms quickly disappearing when the diet was restricted to seal-meat. Skua gulls, which were also obtained, were found to be excellent eating.

The southern sledge expedition undertaken by the Commander, with Lieut. Shackleton and Dr. Wilson, was carried out entirely on the surface of the great ice-sheet, it being found impossible to reach the land, though it was sufficiently near to allow of observations as regards the bearing and altitude of the different land-masses, as well as sketches and photographs. A remarkable feature seems to be the fiord-like openings by which it is penetrated at various points, though the intervening volcanic masses rise into magnificent ranges of mountains. These openings had the appearance of straits, nothing being seen behind, though the state of the ice-sheet opposite them showed that ice must be pressing out through them. On approaching the land at the furthest south, the ice-sheet was found to be separated from it by an immense chasm, the ice-foot resembling that seen elsewhere at the sea-margin of the lands, and forming a complete bar to further progress. The return journey was rendered difficult by the nature of the surface and the prevalent mist.

The further details supplied of Lieut. Armitage's western expedition show that, after proceeding up one large glacier, lying between precipitous granite mountains, a ridge was crossed by a pass 4000 feet above the sea to a second glacier, which had a general trend from southwest to north-east. Its right-hand branch was ascended to a range of remarkably bare granite mountains, the ice surface being much crevassed. A line of sticks set up during the ascent showed a maximum motion of 3 feet 8 inches in twenty-three days. On gaining a height of 9000 feet a smooth, open snow-covered plain stretched to the westward, its surface being soft, with successive crusts nine inches or a foot apart. There were no sastrugi. The whole horizon to the west was clear and unbroken, and the plain appeared to have a slight fall in this direction. Running streams, 7 feet wide, with occasional pools sometimes a mile in diameter, were seen on the return journey, and Bergschrunds 150 feet deep were found at the base of the mountains. Among the other journeys described, those of Dr. Koettlitz for the investigation of the ice and eskerlike lines of debris in the neighbourhood of the Black and Brown Islands are of most interest.

An interesting complement to the narrative of the British expedition has been supplied by the report of Dr. von Drygalski, leader of the German expedition in the Gauss, which was published as a supplement to the official Reichsanzeiger on July io. It describes the voyage from Kerguelen via $\mathrm{a}$ Heard Island to the supposed position of the non-existent 'Termination Land, the southward advance to a previously unknown land, in the vicinity of which winter quarters were established, the scientific work done at the winter station, and the sledge journeys undertaken during the stay. The Gauss was frozen fast in the ice to the north of this land, the pack there remaining stationary owing to the shallowness of the sea over the "Continental Shelf." Only a few miles to the north it appears to be kept constantly in motion by the heavy swell caused by the westerly storms, which would have seriously impeded the scientific work, besides endangering the ship. From the land rose a bare volcanic peak 1200 feet high, which was named the Gaussberg. The Gauss was set free on February 8 by a strong easterly wind, but was caught again temporarily in a somewhat lower latitude, the final start northward being made on April 8, when the lengthening nights were already making navigation difficult.

\section{THE STRUCTURE OF SPECTRA.'}

THIS paper gives a very lucid account of the structure of various types of spectra, special attention being directed to the work on "series" which has been performed during recent years.

After referring to the splendid work performed by Angström and Rowland in establishing trustworthy tables of standard wave-lengths, the author passes on to the evolution of the definite laws which have been found to govern the distribution of lines in the spectra of many elements, comparing the occurrence of similar definite groupings of lines in the spectrum of a substance to the "harmonics" obtained in acoustics.

In 1863 Mascart found that certain groups of lines of characteristic aspect were reproduced in different parts of the spectrum of the same metal, e.g. he found that similar triplets to the "b" group of magnesium were reproduced in the ultra-violet region of the spectrum of that metal. To-day it is known that altogether there are fourteen such groups in the magnesium spectrum, one in the infra-red, the " $b$ " group and twelve in the ultra-violet.

Similarly in the spectrum of sodium there are twelve such "doublets" as that commonly known as $D_{1}$ and $D_{2}$ in the solar spectrum. If these "triplets" and "doublets" are represented on a scale of wave-lengths, they contract. as they approach the ultra-violet, but if they are represented on a scale of frequencies, the groups of the same metal become identical, and are absolutely superimposable. Similar groups have been found for a large number of metals by Kayser and Runge.

The alkaline metals, like sodium, give a series of "doublets," as also do copper and silver, whilst the divalent metais (Mg, Ca, $\mathrm{Sr}: \mathrm{Zn}, \mathrm{Cd}, \mathrm{Hg})$ give triplets, although some of them, e.g. $\mathrm{Hg}$, are so mixed up with other groups that at first this arrangement is difficult to recognise. Here then we have a simple law, which should be credited to Rydberg, viz. "In the spectra of a large number of elements there exist groups which are reproduced several times, the interval which separates the individual lines of each group (when represented on a scale of "frequencies ') being exactly the same for all the groups."

For the alkaline metals the length of the interval which. separates the doublets varies as the square of the atomic. weights, as is shown in the following table:-

$\begin{array}{lrrrrrr}\text { Metal } & & \begin{array}{c}\text { Atomic } \\ \text { weights } \\ (\boldsymbol{P})\end{array} & & \begin{array}{c}\text { Length of } \\ \text { interval } \\ (\nu)\end{array} & & \nu / \mathrm{P}^{2} \times \mathrm{ro}^{4} \\ { }^{2} \mathrm{Li} & \ldots & 7 & \ldots & - & \ldots & - \\ \mathrm{Na} & \ldots & 23 & \ldots & 0.17 & \ldots & 3.25 \\ \mathrm{~K} & \ldots & 39 & \ldots & 0.57 & \ldots & 3.8 \mathrm{I} \\ \mathrm{Rb} & \ldots & 85 & \ldots & 2.34 & \ldots & 322 \\ \mathrm{Cs} & \ldots & 133 & \ldots & 5.45 & \ldots & 3.09\end{array}$

It was then found that these groups arrange themselves in regular series capable of mathematical expression, and in 1885 Balmer found that on plotting the thirteen lines of hydrogen on a curve which had " $m$ " (the number of the line counting in order from " 3 " in the red to " 15 ", in the ultra-violet) for its abscissa and $\mathrm{N}$ (the frequency) for its ordinate, he obtained a perfectly regular curve which could be exactly expressed by the formula

$$
\mathrm{N}=\mathrm{B} / 4-\mathrm{B} / \mathrm{m}^{2} \text {, }
$$

where $\mathrm{B}$ was a constant. Later, Messrs. Hales and Des. landres discovered sixteen other hydrogen lines in the spectra of prominences and various stars, and it was found that these also might be represented by the above formula

The spectra of metals also arrange themselves in similar series, although the relations are not so easily seen at first, because of the overlapping of the other lines. However, the spectrum of potassium may be taken as an example, and we find that on plotting the lines in a similar manner we obtain three such series, known respectively as "the principal," "the first subordinate," and the "second subordinate" series. In each of these series the brightness of the lines decreases as they approach the more 1 "La Structure des Spectres," by Prof. Ch. Fabry, Marseilles, in the Revue Générale des Sciences, No. 5, March 15.

2 The "doublets" for lithium have not been observed, but if the law is applicable in this case the interval would only be oor 6 , which is too small
to be observed.

No. I 76 I, vOL. 68] 